\title{
Copy Number Gain at Xq28 in a Child with Global Developmental Delay Associated with a Variant Form of Hoyeraal-Hreidarsson Syndrome
}

\author{
Lélia L. Gonçalves Ramos ${ }^{a, b}$ Irene Plaza Pinto ${ }^{b, c}$ Rajib Deb ${ }^{b, f}$ \\ Cristiano L. Ribeiro $^{b, c}$ Damiana Mírian da Cruz e Cunha ${ }^{b}$ \\ Lysa Bernardes Minasib, d Antonio M.T. Cordeiro Silva ${ }^{a, g}$ \\ Aparecido D. da Cruz ${ }^{\text {b-e }}$
}

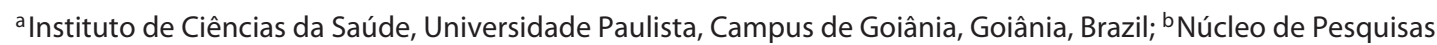
Replicon, Departamento de Ciências Agrárias e Biológicas, Pontifícia Universidade Católica de Goiás, Goiânia, Brazil; ' Programa de Pós-Graduação em Biotecnologia e Biodiversidade, Universidade de Brasília, Brasília, Brazil; dPrograma de Pós-Graduação (Mestrado) em Genética, Pontifícia Universidade Católica de Goiás, Goiânia, Brazil; eLaboratório de Citogenética Humana e Genética Molecular, Secretaria do Estado da Saúde de Goiás, Goiânia, Brazil; ${ }^{f}$ ICAR-Central Institute for Research on Cattle, Meerut, India; ${ }^{9}$ Escola de Ciências Médicas, Farmacêuticas e Biomédicas, Pontifícia Universidade Católica de Goiás, Goiânia, Brazil

\section{Keywords}

Chromosomal microarray analysis · DKC1 - Genetic

syndrome $\cdot$ Global developmental delay

\begin{abstract}
We report the case of a child from Central Brazil with global developmental delay (GDD), syndromic features, and absence of abnormal skin pigmentation, nail dystrophy, and leukoplakia of the oral mucosa, with a rearrangement at Xq28 harboring the $D K C 1$ gene. GTC-banding revealed a male karyotype $(46, \mathrm{XY})$ with no visible numerical or structural alterations. Chromosomal microarray analysis (CMA) showed a $0.36-\mathrm{Mb}$ gain at Xq28 of maternal origin, encompassing 22 genes, including $D K C 1$. Rearrangements and mutations involving this gene have been associated with dyskeratosis congenita, X-linked (OMIM 305000) and HoyeraalHreidarsson syndrome. CMA was a powerful and efficient
\end{abstract}

\section{KARGER}

(C) 2019 S. Karger AG, Basel

E-Mail karger@karger.com

www.karger.com/msy approach to identify a gain at $\mathrm{Xq} 28$ harboring the $D K C 1$ gene in our patient with GDD syndromic features and no cutaneous alterations, suggesting that this variant is associated with the Hoyeraal-Hreidarsson syndrome.

ㄷ) 2019 S. Karger AG, Basel

The Hoyeraal-Hreidarsson syndrome (HHS) is a very rare $\mathrm{X}$-linked multisystem recessive genetic disorder first described by Aalfs et al. [1995]. Clinically, HHS is seen as a severe form of dyskeratosis congenital (DKC), characterized by intrauterine growth retardation, global developmental delay (GDD), neurological impairment, microcephaly, cerebellar hypoplasia, aplastic anemia, and immunodeficiency with progressive bone marrow failure [Bakar et al., 2015; Glousker et al., 2015; Dehmel et al., 2016]. Germline mutations in DKC1, an important telomere biology gene, cause HHS in males. To date, less than 20 patients have been re- 
ported with this syndrome worldwide for which prevalence and incidence rate are unknown, most likely due to its high mortality rate.

DKC1 located in Xq28 encodes for dyskerin pseudouridine synthase 1 , a nucleolar protein which is a constituent of H/ACA ribonucleoprotein particles and plays a role in the pseudouridylation of specific residues in nascent rRNA and snRNA molecules [Mochizuki et al., 2004; $\mathrm{Gu}$ at al., 2008]. DKC1 is also active in stabilizing and maintaining the telomerase, a ribonucleoprotein that uses an RNA template and a reverse transcriptase to add a species-dependent telomere repeat sequence to the $3^{\prime}$ end of the telomeres [Gu et al., 2008]. Dyskerin plays an additional part in nucleocytoplasmic shuttling, DNA damage response, and cell adhesion [Mochizuki et al., 2004; Gu at al., 2008].

Either numerical or structural chromosomal aberrations are considered to be the main cause of unexplained GDD, intellectual disability (ID), and multiple congenital anomalies. Together, aberrant chromosomes account for about $15-30 \%$ of the GDD/ID cases and from this group, $5-10 \%$ occurring predominantly in males could be explained by X-chromosomal aberrations [Rafati et al., 2012; Capalbo et al., 2017; Muthusamy et al., 2017]. Herein, we report a case of microduplication at Xq28 associated with a variant form of HHS in a Brazilian boy with GDD and syndromic features, lacking abnormal skin pigmentation, nail dystrophy, and leukoplakia of the oral mucosa.

\section{Patient and Methods}

\section{Case Presentation}

The patient is a 1-year-old boy born by cesarean delivery at 34 weeks of gestation to a nonconsanguineous couple, a 21-year-old mother and 30-year-old father. His birth weight was 1,640 g, crown-heel length was $39 \mathrm{~cm}$, head circumference $32 \mathrm{~cm}$, and Apgar score 4 at $1 \mathrm{~min}$ and 8 at $5 \mathrm{~min}$. After birth, the newborn went into cardiorespiratory arrest and remained at an intensive care unit for 36 days. Physical examination of the child at 1 year of age revealed GDD, with a height of $64 \mathrm{~cm}$ and weight of 5,450 g. His craniofacial dysmorphisms included a large nasal bridge, hypertelorism, long philtrum, thin upper and lower lips, and retrognathism. He also had low-set ears, enlarged eyebrows, progeria, foramen ovale, and secondary adrenal insufficiency. On the other hand, the child lacked abnormal skin pigmentation, nail dystrophy, and leukoplakia of the oral mucosa. Assistant physicians from the public health system referred the patient to the genetic services (Laboratory of Human Cytogenetics and Molecular Genetics) of the State Health Secretary and the Replicon Research Group of the School of Agricultural and Biological Sciences, Pontifical Catholic University in Central Brazil.

Copy Number Gain at Xq28 Associated with Hoyeraal-Hreidarsson Syndrome
Materials and Methods

Peripheral blood from the child and his parents were collected. Genomic DNA was isolated from whole blood samples using the Illustra Blood Genomic Prep Mini Spin Kit (GE Healthcare Life Sciences, USA), following the manufacturer's instructions. Quality and quantity of genomic DNA was assessed by spectrophotometer readings.

Conventional cell cultures, harvesting, and G-banding at the level of $>550$ bands were performed for the entire family, following modified procedures [Verma and Babu, 1995]. Chromosome analyses were performed using a Zeiss Axioscope ${ }^{\circledR}$ (Göttingen, Germany) with the aid of IKAROS ${ }^{\circledR}$ software (Metasystems Corporation, Altlussheim, Germany). The analyses were carried out on the child and his parents to establish whether the DNA rearrangements were de novo or inherited.

A total $250 \mathrm{ng}$ of DNA for each sample was digested with NspI, ligated, PCR amplified and purified, fragmented, biotin-labeled, and hybridized for use in a GeneChip ${ }^{\circledR}$, CytoScan $^{\mathrm{TM}} \mathrm{HD}$ (Affymetrix, Santa Clara, CA, USA). The array was specifically designed for cytogenetic research, including 2.7 million copy number variation markers. CEL files obtained by scanning the arrays were analyzed using the Chromosome Analysis Suite ${ }^{\circledR}$ software (Affymetrix). Gains and losses were set at a minimum of 50 and 25 markers, respectively, and $100 \mathrm{~kb}$ length.

\section{Results}

Karyotyping showed a male karyotype (46,XY). However, CMA detected a 356.77-kb gain - maternally inherited - at Xq28, arr[hg19] Xq28(153,792,708-154,149,474) $\times 2$ mat, harboring the following genes: IKBKG, LINC00204B, LINC00204A, CTAG1A, CTAG1B, CTAG2, GAB3, DKC1, SNORA36A, MIR644B, SNORA56, MPP1, CXorf68, F8, H2AFB3, H2AFB1, F8A1, F8A3, F8A2, MIR1184-3, MIR1184-2, and MIR1184-1 (Fig. 1). Among these, the $D K C 1$ gene is related to $\mathrm{DKC}, \mathrm{X}$-linked (OMIM 305000) and HHS.

\section{Discussion}

Herein, we report the first case of a copy number gain at Xq28 affecting the $D K C 1$ gene in a child from Goiás State in Central Brazil. The proband exhibited GDD, short stature, craniofacial dysmorphisms, including a large nasal bridge, hypertelorism, long philtrum, thin upper and lower lips, and retrognathism. The clinical description of our patient was similar to the patients described by Hoyeraal et al. [1970], Hreidarsson et al. [1988], and Aalfs et al. [1995], but abnormal skin pigmentation, nail dystrophy, and leukoplakia of the oral mucosa were absent. 


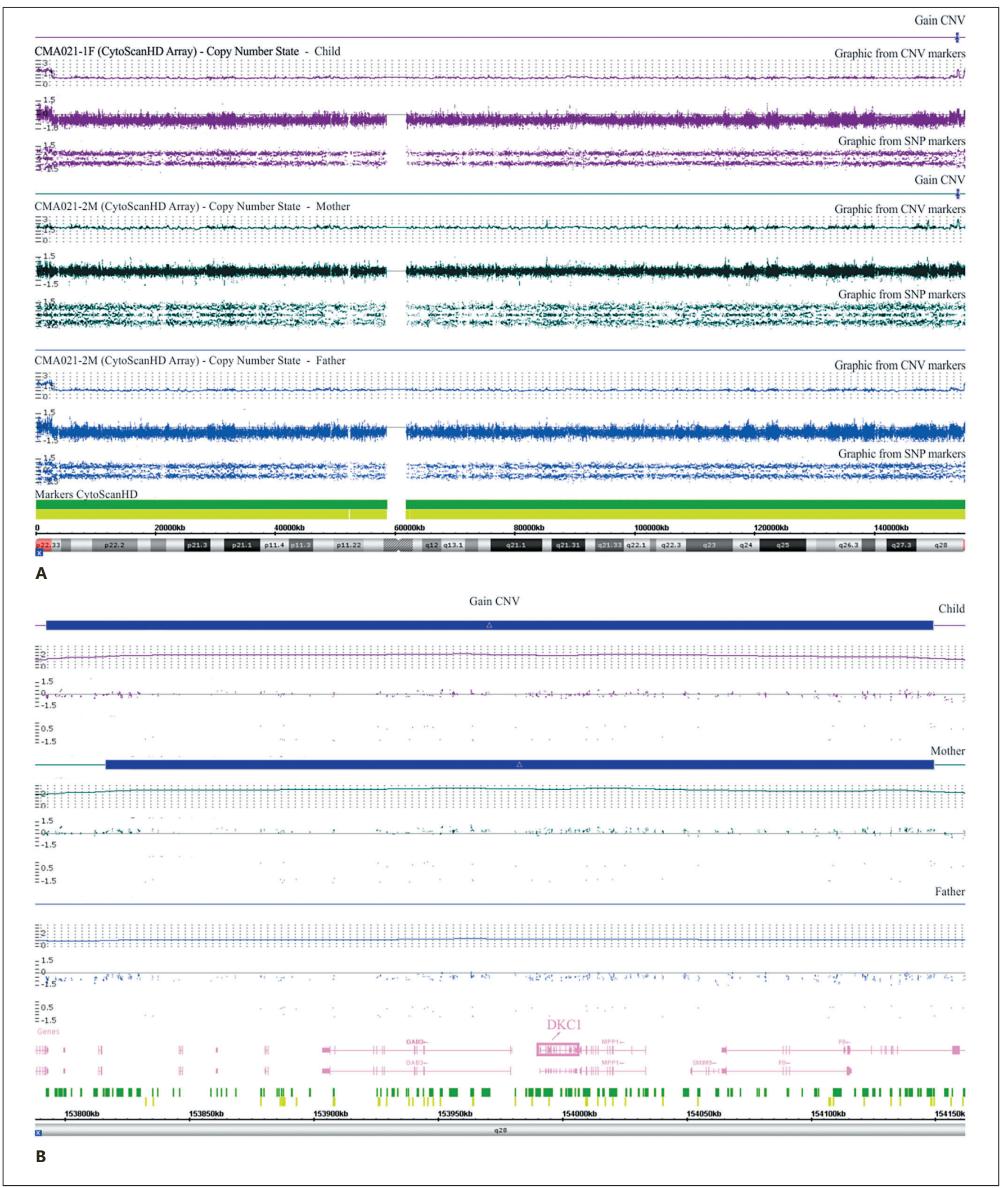

Fig. 1. A Chromosomal microarray analysis of chromosome $X$ from the child and his mother with a copy number gain at Xq28. B Zoom into the CNV region Xq28. Genes are shown in pink. 
The classical phenotype of HHS is commonly associated with the lack of function of $D K C 1$ mostly due to mutations that inactivate the gene. Our proband showed a gain at Xq28; thus, he most likely had 2 copies of the gene, which led to the deviation of the frequently described phenotype of HHS in males who are hemizygous for the gene. Similar to genomic variations observed in other syndromes, such as in developmental neuropsychiatric disorders [Hiroi et al., 2013], duplications and deletions may coincidently affect genes that might induce the same phenotypes despite gene-dose deviation in either direction. Thus, here we report a variant form of HHS due to a gain in $D K C 1$ at $\mathrm{Xq} 28$, reinforcing $\mathrm{CNV}$-associated traits that are yet to be clearly understood.

Both $\mathrm{HH}$ and DKC syndromes are $\mathrm{X}$-linked, and $\mathrm{X}$ chromosome inactivation is an important process to understand the potential outcomes in heterozygous female carriers of $D K C 1$ mutations. A study by Alder et al. [2013] showed $100 \%$ skewing in $\mathrm{X}$-inactivation in female carriers of heterozygous mutations in DKC1. Thus, heterozygous females may show DKC-like phenotype/genotype correlation, pending the inactivation of the unaffected chromosome [Xu et al., 2016]. Although, in our report, the microduplication seen in the child was maternally inherited, the mother had no clinical manifestation of DKC or HHS, most likely due to the inactivation of the X chromosome harboring the 2 copies of $D K C 1$.Thus, the mendelian recurrence risk estimates for our family are 50 and $25 \%$ for female carries and affected males, respectively. The number of cases of HHS and DKC are scarce, preventing us from any inferences regarding the potential contribution of incomplete penetrance or variable expressivity in HHS patients.

The biological mechanism subjacent to HHS progression remains unknown. Nonetheless, some studies have shown that nonfunctional telomeres play an important etiological role in the development of DKC, HHS, and several other genomic disorders [Glousker et al., 2015; Dehmel et al., 2016; Xu et al., 2016]. Finally, our findings suggest that imbalances in gene dosage in addition to mutations in the DKC1 gene can lead to telomere-related phenotypes.

\section{Conclusion}

CMA identified a copy number gain at Xq28 involving the $D K C 1$ gene in a boy from Central Brazil, with GDD and syndromic features. This genotype-phenotype correlation enabled the diagnosis of a variant form of HHS, contributing to adequate clinical management, genetic counseling, and a better follow-up of the proband and his family.

\section{Acknowledgment}

The authors wish to thank Dr. Rinaldo W. Pereira and the Rede ExeGenes for supporting the improvement of genetic diagnosis in Central Brazil. We also wish to thank TWAS, Italy for providing a fellowship to R.D. The authors manifest their gratitude to Mr. Sean M. Quail for proofreading the manuscript.

\section{Statement of Ethics}

The parents of the proband gave written informed consent approved by the Ethics Committee on Human Research at the Pontifical Catholic University of Goiás (CEPPUC/GO), under the protocol number CAAE 0051.0.168.000-11.

\section{Disclosure Statement}

The authors have no conflicts of interest to declare.

\section{Funding Sources}

This work was sponsored by grants from Conselho Nacional de Desenvolvimento Científico e Tecnológico (CNPq; Edital 031/564465/2010-10) and Fundação de Amparo à Pesquisa do Estado de Goiás (FAPEG; 2011.6002.19.1847.1134-03).

\section{Author Contributions}

L.L. Gonçalves Ramos, I. Plaza Pinto, and A.D. da Cruz contributed to conception and design of the research. Formal analysis was done by I. Plaza Pinto. L.L. Gonçalves Ramos, I. Plaza Pinto, and L. Bernardes Minasi performed the investigations. C. Luiz Ribeiro, D. Mírian da Cruz e Cunha, I. Plaza Pinto, L. Bernardes Minasi, and R. Deb developed the methodology. A.D. da Cruz and A.M.T. Cordeiro Silva supervised the study. L.L. Gonçalves Ramos, I. Plaza Pinto, R. Deb, and A.D. da Cruz wrote the manuscript, and the last 2 authors reviewed and edited the work. 


\section{References}

Aalfs CM, van den Berg H, Barth PG, Hennekam RC: The Hoyeraal-Hreidarsson syndrome: the fourth case of a separate entity with prenatal growth retardation, progressive pancytopenia and cerebellar hypoplasia. Eur J Pediatr 154:304-308 (1995).

- Alder JK, Parry EM, Yegnasubramanian S, Wagner CL, Lieblich LM, et al: Telomere phenotypes in females with heterozygous mutations in the dyskeratosis congenita $1(D K C 1)$ gene. Hum Mutat 34:1481-1485 (2013).

- Bakar Ö, Işik U, Canpolat C, Alanay Y: HoyeraalHreidarsson syndrome: an extremely rare dyskeratosis congenita phenotype. Pediatr Dermatol 32:263-266 (2015).

Capalbo A, Rienzi L, Ubaldi FM: Diagnosis and clinical management of duplications and deletions. Fertil Steril 107:12-18 (2017).

Dehmel M, Brenner S, Suttorp M, Hahn G, Schützle H, et al: Novel mutation in the DKC1 gene: neonatal Hoyeraal-Hreidarsson syndrome as a rare differential diagnosis in pontocerebellar hypoplasia, primary microcephaly, and progressive bone marrow failure. Neuropediatrics 47:182-186 (2016).
Glousker G, Touzot F, Revy P, Tzfati Y, Savage SA: Unraveling the pathogenesis of HoyeraalHreidarsson syndrome, a complex telomere biology disorder. Br J Haematol 170:457-471 (2015).

Gu BW, Bessler M, Mason PJ: A pathogenic dyskerin mutation impairs proliferation and ac tivates a DNA damage response independent of telomere length in mice. Proc Natl Acad Sci USA 105:10173-10178 (2008).

Hiroi N, Takahashi T, Hishimoto A, Izumi T, Boku S, Hiramoto T: Copy number variation at 22q11.2: from rare variants to common mechanisms of developmental neuropsychiatric disorders. Mol Psychiatry 18:1153-1165 (2013).

Hoyeraal HM, Lamvik J, Moe PJ: Congenital hypoplastic thrombocytopenia and cerebral malformations in two brothers. Acta Pediatr Scand 59:185-191 (1970).

Hreidarsson S, Kristjansson K, Johannesson G, Johannsson JH: A syndrome of progressive pancytopenia with microcephaly, cerebellar hypoplasia and growth failure. Acta Pediatr Scand 77:773-775 (1988).
Mochizuki Y, He J, Kulkarni S, Bessler M, Mason PJ: Mouse dyskerin mutations affect accumulation of telomerase RNA and small nucleolar RNA, telomerase activity, and ribosomal RNA processing. Proc Natl Acad Sci USA 101: 10756-10761 (2004)

Muthusamy B, Selvan LDN, Nguyen TT, Manoj J, Stawiski EW, et al: Next-generation sequencing reveals novel mutations in X-linked intellectual disability. OMICS 21:295-303 (2017).

Rafati M, Seyyedaboutorabi E, Ghadirzadeh MR, Heshmati Y, Adibi H, et al: "Familial” versus "Sporadic" intellectual disability: contribution of common microdeletion and microduplication syndromes. Mol Cytogenet 5:9 (2012)

Verma RS, Babu A: Human Chromosomes: Principles and Techniques (McGraw-Hill Inc., New York 1995).

Xu J, Khincha PP, Giri N, Alter BP, Savage SA, Wong JM: Investigation of chromosome $\mathrm{X}$ inactivation and clinical phenotypes in female carriers of DKC1 mutations. Am J Hematol 91:1215-1220 (2016). 